SRI LANKAN JOURNAL OF ANAESTHESIOLOGY

Volume 17 Number 2, June 2009

\title{
Editorial I
}

\section{HEALTH SECTOR DEVELOPMENT PROJECT}

The Ministry of Health with funding from the World Bank undertook the Sri Lanka Health Sector Development Project. The aim of which was to further develop the free health services delivered by the Ministry of Health to its citizens through out the country.

As it was not feasible to carry out the project through out the country two provinces were ear marked to carry out a pilot project. The two provinces were the Southern Province and the Uva Province.

The Ministry was of the view that this project should be carried out by the professional Colleges of the different specialties. The College of Anaesthesiologists too was invited to be a stakeholder in this project to which the College whole-heartedly agreed. The payment for the work carried out by the College will be by the World Bank.

The activities of the project were to 1 . Assess the existing health delivery system as regards infra structure, manpower and resources 2. To detect the gaps in the existing health delivery system 3 . To take corrective measures, both short term and long term to rectify the gaps thus improving and optimizing the health delivery system

1. Assess the existing health delivery system $-\mathrm{A}$ survey was carried out in the hospitals that belonged to the Southern and Uva provinces with regard to infra structure, resources available and manpower. The hospitals were graded according to facilities available and the population it catered to, if necessary, upgrading was advised.

2. To detect gaps in the health delivery system According to the above grading, the gaps which needed to be put right to optimize the delivery of health services by each hospital, were taken note of.

3. Corrective measures - A report was made available to the Ministry of Health regarding the improvement of infra structure, manpower and resources in the hospitals of the two provinces. Correcting this was beyond the capacity of the College. Lack of knowledge by the medical staff, which would hinder the management of the patient or where patient management could be improved, was taken over by the college to be put right.

The areas, which the College decided to look into, were 1. Anaesthesia 2. Critical care 3. Resuscitation 4.Pain and trauma management, which are the specialty areas that the College is involved in.

\section{Corrective measures}

\section{Guidelines}

The College put forward guidelines in areas of Anaesthesia, Critical care, Pain management and Trauma care. These were distributed to the two provinces to be made use of as "helping tools" in their management of patients. A survey will be carried out later this year to assess how effective these guidelines have been in patient management specially to the junior doctor who is the first recipient of the patient. The survey will be carried out among all grades of staff relevant for the management and will not be restricted only to the junior doctor. The survey will also call for comments so that changes can be made wherever necessary, to make these guidelines absolutely fool proof. 
The long-term corrective measure would be, to make these guidelines National guidelines by the Ministry of Health to be made use of throughout the country. This will undoubtedly help the juniors working in remote hospitals away from consultant supervision. This will lead to better health care even in the remotest of areas in the island.

\section{Workshops}

Gaps in the knowledge, which were identified in the survey, were taken into consideration and training modules along these lines were formulated by the college. These modules thereafter were designed as workshops to be carried out in the two provinces. Six workshops were designed on Anaesthesia, critical care and resuscitation. They are 1. Cardiopulmonary resuscitation 2. Intensive care 3. Transport of the critically ill 4.Anaesthetic and intensive care management of Obstetric emergencies 5. Theatre training and 6. Anaesthetic complications. All six workshops were carried out in the two provinces by the module coordinators who were consultants in the two provinces. They designed the workshops with lectures, panel discussions and workstations, which gave hands on training to improve skills of medical staff. These workshops were well appreciated by the participants. A trainee's manual with lectures and expected skills were given to each participant. MCQs were designed as a form of assessment before and after the workshop.

This not only gave the trainer and in-depth knowledge of the knowledge and skills of the participant but also what was achieved at the end of the training. This is a very fulfilling task to any consultant and is really an indirect reward. It is also a means of showing the participant an improvement in his or her patient care with immediate effect. This will give confidence to the junior doctor working alone or as the first recipient of the patient.

As a long term measure the college will be more than happy to sponsor such workshops in any part of the country if the members make the request.

\section{The role of the College}

The World Bank will be concluding this project at the end of this year. It is now the duty of the College to make sure that we continue the good work so that our specialty will benefit by this and we will be able to deliver the best possible patient delivery service to our fellow countrymen. In this regard it is essential that we 1. Upgrade the National guidelines on a regular basis 2. Ensure that our juniors are competent in delivery of service by conducting regular workshops 3 . Assisting the ministry with regard to infrastructure development in conforming to laid down guidelines when constructing new theatres and intensive care units and manning them.

\section{Shirani Hapuarachchi* \\ Consultant Anaesthetist, Neuro Surgical \\ Department, The National Hospital of Sri Lanka \\ * Corresponding author. E-mail: hapu@ sltnet.lk}

